\title{
Esterification of glycerol with acetic acid over Lewatit catalyst
}

\author{
Lucky Setyaningsih", Fahmi Siddiq, and Aqila Pramezy \\ Department of Chemical Engineering, Islamic University of Indonesia, Yogyakarta, INDONESIA
}

\begin{abstract}
Tri Acetyl Glycerol or triacetin is one of the glycerol derivative products which can be used as additives in liquid fuels (octane boosters) to reduce knocking on the machine. The use of triacetin as octane booster is considered very promising because it comes from renewable and environmentally friendly raw materials. The resulting glycerol-based additives are suitable for gasoline, biodiesel and diesel. In this study glycerol esterification with acetic acid over Lewatit catalyst was investigated. The effects of various parameters, such as reaction temperature, weight of catalyst and molar ratio of glycerol to acetic acid were studied and the optimum condition for the triacetin synthesis are $100^{\circ} \mathrm{C}, 1: 7$ mole of ratio and $3 \%$ weight of catalys
\end{abstract}

\section{Introduction}

Biodiesel is one of the renewable energy sources that can be an alternative to the use of petroleum. Biodiesel is an alternative fuel from renewable natural resources that have a positive impact, especially the emissions of gases produced more environmentally friendly. Biodiesel production will produce glycerol as a by-product of about $10 \%$ (by weight) of biodiesel production [1]. The increasing production of biodiesel will be followed by an increase in the amount of glycerol produced as a byproduct, therefore an effort is needed to utilize glycerol as a raw material for the manufacture of other chemicals.

Tri Acetyl Glycerol or triacetin is one of the glycerol derivative products which can be used in various industries, e.g. emulsifiers, plasticizers, additives in the coating and paint industries, and can also be used as additives in liquid fuels (octane boosters) to reduce knocking on the machine [2]. The commonly used Octane booster is tetraethyl lead (TEL, $\left.\mathrm{Pb}\left(\mathrm{C}_{2} \mathrm{H}_{5}\right)_{4}\right)$ but its use will form a thin layer of lead in an atmosphere which is harmful for living things. The use of triacetin as octane booster is considered very promising because it comes from renewable and environmentally friendly raw materials. The resulting glycerol-based additives are suitable for gasoline, biodiesel and diesel.

In this study triacetin will be produced from esterification process of glycerol and acetic acid. To increase the reaction rate and yield of product, in the synthesis process of glycerol derivative products into fuel additive materials used catalyst. The choice of catalyst type for a reaction is based on several considerations, namely: porous structure to produce large surface area as active site provider, thermal stability to temperature change and has high acidity.

The reaction of triacetin formation is an esterification reaction with glycerol and acetic acid reactants, the esterification reaction of glycerol is a slow reaction. In previous studies, triacetin formation of glycerol and acetic acid without catalyst takes more than 4 hours. Meanwhile, by using aminosulfonic acid catalyst it was obtained a yield of $90 \%$ [3]. Esterification reaction with a phosphotungstic acid catalyst, reactant ratio of $3.8 \%$, a temperature of $135-155^{\circ} \mathrm{C}$ and a reaction time of 7 hours yielded $84.6 \%$ [4]. The effect of the use of various solid catalysts for the preparation of triacetin was carried out by Gonsalves. The catalysts used were Amberlist-15, K 10, Niobic acid, HZMS-5 and HUSY. From the various catalysts the success of triacetin was achieved only when using Amberlist- 15 and K 10 catalysts with selectivity of only $13 \%$ and $5 \%$. While the use of other catalysts only get monoacetin and diacetin although its conversion can reach more than $90 \%$ [5]. Gelosa made triacetin with packed bed reactor with 36 grams Amberlyst catalyst stuffing material which run on column with internal diameter of $1.5 \mathrm{~cm}$ long and $44 \mathrm{~cm}$ long. When used the comparison of glycerol reactants and acetic acid 2: 9 , with flow rate of $0.3 \mathrm{~cm}^{3} / \mathrm{min}, 50 \%$ acetic acid conversion was obtained [6]. The selectivity of diacetylglycerol (DAG) and triacetylglycerol (TAG) mixtures after reacting for 4 hours can reach more than $80 \%$. The reaction is carried out in an autoclave reactor at a temperature of $100-150^{\circ} \mathrm{C}$ and a pressure of about $4 \mathrm{~atm}$ [7].

In this research, triacetin synthesis process will be done through esterification reaction with glycerol and acetic acid using lewatit catalyst. The use of lewatit catalysts is intended to facilitate the separation of the reaction product [8]. In addition, the utilization of lewatit catalyst which is an ion exchange resin is expected to provide alternative materials supporting the development of glycerol derivative products.

\section{Methodology}

Prior to the use the catalyst is activated by using a $\mathrm{HCl} 1$ $\mathrm{N}$ solution of $200 \%$ of the catalyst volume. The catalyst mixture is stirred using a magnetic stirrer for 30 minutes 
and rinsed with distillated water to neutral $\mathrm{pH}$. Glycerol with a certain volume and the lewatit catalyst is heated in a three-neck flask, while acetic acid is heated in a separate container. After the second temperature of the reactant reaches the reaction temperature, acetic acid is introduced in a three-neck flask containing glycerol and a catalyst. During the reaction, stirring at a rate of $175 \mathrm{rpm}$ and temperature is kept constant according to the reaction temperature. The research was conducted by varying the mole ratio of reactants (glycerol: acetic acid) 1: 6, 1:7 and 1: 8 , reaction temperature $90^{\circ} \mathrm{C}, 100^{\circ} \mathrm{C}$ and $110^{\circ} \mathrm{C}, 3 \%$ catalyst weight and $175 \mathrm{rpm}$ stirring rate. Samples were taken every 15 minutes and the reaction was run for 90 minutes.

Data obtained from the study were free glycerol levels at each time interval of 15 min obtained in each process condition. This data is then used to evaluate the conversion value as a function of time. Glycerol levels can be calculated by the following formula:

$$
\operatorname{glycerol}\left(\%_{\text {weight }}\right)=\frac{2,302(B-S)(N)\left(\rho_{a}\right)(450)(170)}{50\left(w_{1}\right)\left(w_{2}\right)}
$$

Where $\mathrm{B}$ is volume of $\mathrm{Na}_{2} \mathrm{~S}_{2} \mathrm{O}_{3}$ titration for blank solution $(\mathrm{mL}), \mathrm{S}$ is volume of $\mathrm{Na}_{2} \mathrm{~S}_{2} \mathrm{O}_{3}$ titration for sample solution $(\mathrm{mL}), \mathrm{N}$ is normality of $\mathrm{Na}_{2} \mathrm{~S}_{2} \mathrm{O}_{3}$ solution, $\rho_{a}$ is distilled density $(\mathrm{g} / \mathrm{mL}), w_{1}=$ initial sample weight $(\mathrm{g}), w_{2}=$ diluted sample weight $(\mathrm{g})$.

\section{Result and Discussion}

\subsection{Effect of Temperature}

The data of glycerol conversion versus time at various temperatures can be seen in Table 1 and Figure 1.

Table 1. Glycerol conversion at various temperatures

\begin{tabular}{|c|c|c|c|}
\hline \multirow{2}{*}{$\begin{array}{c}\text { Time } \\
\text { (minute) }\end{array}$} & \multicolumn{3}{|c|}{ Conversion of Glycerol (\%) } \\
\cline { 2 - 4 } & $\mathbf{T = \mathbf { 9 0 } ^ { \circ } \mathbf { C }}$ & $\mathbf{T}=\mathbf{1 0 0}^{\circ} \mathbf{C}$ & $\mathbf{T}=\mathbf{1 1 0}^{\circ} \mathbf{C}$ \\
\hline 0 & 0 & 0 & 0 \\
\hline 15 & 50.55 & 50.40 & 60.92 \\
\hline 30 & 54.76 & 56.80 & 62.43 \\
\hline 45 & 55.34 & 58.46 & 63.31 \\
\hline 60 & 57.00 & 59.33 & 64.82 \\
\hline 75 & 57.91 & 63.45 & 66.03 \\
\hline 90 & 58.56 & 66.91 & 66.38 \\
\hline
\end{tabular}

Based on Table 1 and Figure 1, it appears that there is a spike in conversion shortly after the catalyst is added to the reactor. The same is also reported on the esterification of ethanol and acetic acid by using a monoplus s-100 lewatit catalyst [2]. The esterification of glycerol with myristic acid using a sulphated zirconia catalyst, when the catalyst is added, there is a spontaneous reaction that causes the acid conversion to rise. As the acid conversion increases, the water concentration formed also increases with the same trend. Water has the ability to deactivate acidic solid catalysts due to its high affinity to the acidic active site of the catalyst [9]. Thus it can be understood that after a high rate of conversion spikes, the reaction rate decreases as the activity of the catalyst decreases. The same is true of the use of other solid acid catalysts such as Amberlyst-15 [10].

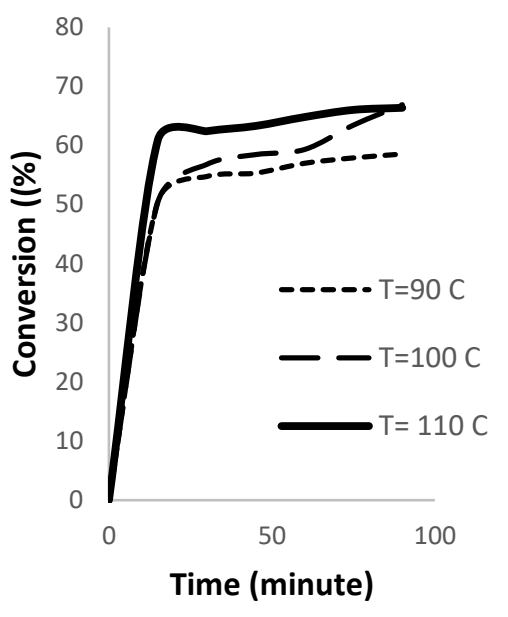

Fig. 1. Correlation between Glycerol conversion versus time at various temperatures

The observed reaction rate is the rate of reaction after the spontaneous reaction occurs, so the resulting graph is relatively sloping. The observed trend of Figure 1 is that the higher the temperature and the longer the reaction time, the conversion tends to increase. This is because with the rise of reaction temperature, the energy of reagent molecules increases in overcoming the activation energy. The reactant molecules will move faster so that the frequency of collisions between molecules will increase and the reaction rate becomes faster. The increase in reaction rate is indicated by the higher reactant conversion. This corresponds to the Arrhenius equation as follows:

$$
k=A \cdot e^{\frac{-E}{R T}}
$$

Equation 2 shows that the temperature is directly proportional to the rate constant of the reaction, where as the reaction temperature increases the reaction rate constant increases so that the reaction rate was faster and the conversion was higher. The same phenomenon also demonstrated in experiment using an Indion $225 \mathrm{Na}$ catalyst [2], a natural and physically activated Zeolite catalyst [11] and Amberlyst-15 as a catalyst [6].

At the end of reaction time, the highest conversion was obtained at temperature $100^{\circ} \mathrm{C}$ with conversion equal to $66.91 \%$, while the lowest conversion was obtained at $80^{\circ} \mathrm{C}$ with conversion of $58.59 \%$. According to the theory, the maximum conversion should be achieved at a temperature of $110^{\circ} \mathrm{C}$, but in this study it did not occur. This is due to the temperature of $110^{\circ} \mathrm{C}$ of Lewatit catalyst which is used to change the color from yellow to dark brown indicating deactivation of the catalyst. The deactivation is caused by high experimental temperature near its maximum temperature, so the catalyst cannot retain under such conditions.

From the research it was obtained a fairly high conversion. This can be compared with other research. In esterification of glycerol carried out by Zhu using AgPW catalysts achieved $96.8 \%$ conversion [12] and $100 \%$ 
conversion can be achieved in research conducted by Gao using Graphene Oxide catalyst at $120^{\circ} \mathrm{C}$ [13]. This is possible because Graphene Oxide and AgPW catalysts are more resistant to high temperatures for longer periods than Lewatit catalysts, so that the conversion becomes higher and the activated natural zeolite catalyst has a better ability to direct esterification reactions.

\subsection{Effect of Molar Ratio of Reactant}

From the experiment of various temperature variations obtained the optimum temperature is $100^{\circ} \mathrm{C}$. Armed with the optimum temperature, the experiment of variation of reactant mole ratio was carried out at $100^{\circ} \mathrm{C}$. The molar ratio of glycerol reactants to acetic acid was 1:6, 1: 7 and 1: 8 . Meanwhile, other variables were kept constant which was $3 \%$ by weight catalyst and $100^{\circ} \mathrm{C}$ reaction temperature. The data of glycerol to time conversion on various reactant variations can be seen in Table 2 and Figure 2.

Table 2. Glycerol conversion at various molar ratio of reactant

\begin{tabular}{|c|c|c|c|}
\hline \multirow{2}{*}{$\begin{array}{c}\text { Time } \\
\text { (minute) }\end{array}$} & \multicolumn{3}{|c|}{ Conversion of Glycerol (\%) } \\
\cline { 2 - 4 } & $\mathbf{1 : 6}$ & $\mathbf{1 : 7}$ & $\mathbf{1 : 8}$ \\
\hline 0 & 0 & 0 & 0 \\
\hline 15 & 50.55 & 56.62 & 60.12 \\
\hline 30 & 56.80 & 60.79 & 65.60 \\
\hline 45 & 58.46 & 66.44 & 67.79 \\
\hline 60 & 59.33 & 66.70 & 68.73 \\
\hline 75 & 63.45 & 70.01 & 73.42 \\
\hline 90 & 66.91 & 73.36 & 73.16 \\
\hline
\end{tabular}

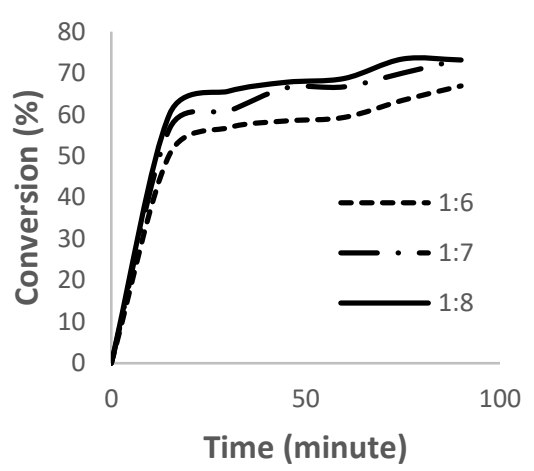

Fig. 2. Correlation between Glycerol conversion versus time at various molar ratio of reactant

The mechanism of the reaction of triacetin formation in an esterification reaction between glycerol and acetic acid is as follows:

\section{Glycerol +3 Acetic Acid $\leftrightarrow$ Triacetin $+3 \mathrm{H}_{2} \mathrm{O}$}

Stoichiometrically, the esterification reaction to produce one mole of triacetin and three moles of water requires one mole of glycerol and three moles of acetic acid. However, because the esterification reaction is a reversible reaction so that acetic acid can be excessive to shift equilibrium toward the product.

From Table 2 and Figure 2 it can be seen that the higher the mole ratio of glycerol reactants than acetic acid, the higher the conversion value of acetic acid achieved. In a molar ratio of 1: 6 to 1: 7 reactants there was a considerable increase in conversion. However, in the molar ratio the 1: 7 to $1: 8$ reactants produce a coincident graph which means that the increase in the mole ratio of the reactant is not very influential. From these results it can be concluded that the highest conversion is obtained at the mole ratio of $1: 7$ reactant at $100^{\circ} \mathrm{C}$ temperature which was $73.36 \%$, while the lowest conversion of $66.91 \%$ was obtained in the reagent mole ratio of $1: 6$. This shows that the mole ratio of reactants gave a significant effect on the conversion of acetic acid. As the mole ratio of the larger reactant increases, it will affect the rate of the reaction that goes faster with the increase of conversion. According to Satriadi, if the concentrations of reactants get higher where the large concentrations of substances contain more number of particles, so the particles are composed more densely than the substances with low concentration. Particles that are closer together will more often collide so that the possibility of reaction is getting bigger [14].

The effect of the reactant mole ratio was very visible at the start of the reaction (from $\mathrm{t}=0$ to $\mathrm{t}=15$ minutes) as shown in Table 2 and Figure 2 above, where the resulting conversion is quite large with a very short time lag of 15 minutes. This is similar to the research conducted by Nuryoto where at the beginning of the reaction, the reaction goes very quickly and then the reaction goes slow [2]. This occurs because of the effect of water produced as a by-product, where in the presence of water the reaction will tend to shift to the left and water has a very strong attraction among the components present in the system that will greatly affect the rate of diffusion And the rate of reaction [6].

In a study conducted by Gao an increase in the mole ratio of glycerol/acetic acid from 1: 2 to 1: 6 leads to an increase in conversion, this is because the excess acetic acid will shift equilibrium toward the product, thereby increasing the formation of monoacetin and diacetin [13]. Increasing in the mole ratio of glycerol/acetic acid from 1: 6 to $1: 8$ leads to a decrease in glycerol conversion, this is due to a sharp decrease in glycerol concentration to the total solution volume.

\subsection{Effect of Weight Catalyst}

The effect of percent weight of the catalyst will be studied on the basis of experiments carried out by varying the catalyst weight by $2 \%, 3 \%$ and $5 \%$ by weight of the catalyst to the glycerol reactant. Meanwhile other variables such as temperature and reactant mole ratios are maintained at $100^{\circ} \mathrm{C}$ and 1: 7. The conversion value obtained from each experiment will be compared to determine the effect of catalyst weight increase on conversion to glycerol. The relationship between conversion and time on various percent weight of the catalyst is presented in Table 3 and Figure 3.

From Table 3 and Figure 3 it is seen that the conversion value of glycerol to triacetin by esterification reaction increases with increasing catalyst concentration 
or percent weight of catalyst used. The observed trend of Fig. 3 is the weight of the catalyst increase from $2 \%$ to $3 \%$ of significant conversion increments. While the increase in catalyst weight from $3 \%$ to $5 \%$ increase in conversion is not too significant. although the resulting graph fluctuates but generally it can be concluded that there was no significant difference between catalyst weight $3 \%$ and $5 \%$. Thus it can be concluded that the weight of the catalyst $3 \%$ is the weight of the optimum catalyst.

Table 3. Glycerol conversion at various weight of catalyst

\begin{tabular}{|c|c|c|c|}
\hline \multirow{2}{*}{$\begin{array}{c}\text { Time } \\
\text { (minute) }\end{array}$} & \multicolumn{3}{|c|}{ Conversion of Glycerol (\%) } \\
\cline { 2 - 4 } & $\mathbf{2 \%}$ & $\mathbf{3 \%}$ & $\mathbf{5 \%}$ \\
\hline 0 & 0 & 0 & 0 \\
\hline 15 & 48.38 & 50.40 & 49.04 \\
\hline 30 & 49.83 & 56.80 & 56.28 \\
\hline 45 & 52.10 & 58.46 & 60.37 \\
\hline 60 & 53.58 & 59.33 & 65.35 \\
\hline 75 & 55.16 & 63.45 & 66.45 \\
\hline 90 & 56.28 & 66.91 & 66.02 \\
\hline
\end{tabular}

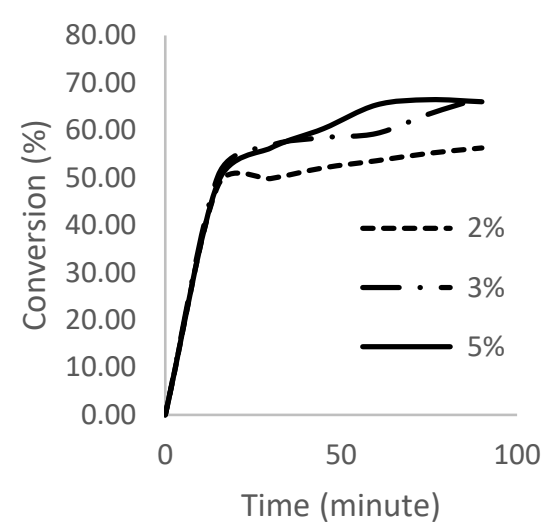

Fig. 3. Correlation between Glycerol conversion versus time at various weight of catalyst

At the end of the reaction time. the highest conversion was obtained at $3 \%$ catalyst weight with a conversion of $66.91 \%$. while the lowest conversion was obtained at $2 \%$ percent catalyst weight with a conversion of $56.28 \%$. Another phenomenon seen from Figure 3 is the increase in glycerol conversion as a function of time is quite gentle and volatile. This was because the number of active sites available on the catalyst was close to the maximum required by the reactants. The same phenomenon is also shown in the study conducted by Yadav where in percent weight of catalyst $5 \%$ it appears that the conversion did not increase compared with the use of 3\% catalyst. This may be because at the weight of the catalyst $5 \%$ there is no perfect mixing due to the catalyst solid density in the solution being large enough to reduce the contact area between the catalyst and the reactants. In addition, the high concentration of solids in the solution allows the dead zone within the reactor.

\section{Conclusion}

1. The conversion value increase with increasing temperature, mole ratio of reactant and the weight of the catalyst.

2. The optimum condition for the triacetin synthesis are $100^{\circ} \mathrm{C}, 1: 7$ mole of ratio and $3 \%$ weight of catalyst.

\section{References}

1. G. Knothe, J. Van Gerpen, J. Krahl, Encyclopedia of Chemical Technology, 11, 921 (2005)

2. Nuryoto, H. Sulistiyo, S.S. Rahayu, Sutijan, Jurnal Rekayasa Proses, Kinetika Reaksi Esterifikasi Gliserol dengan Asam asetat menggunakan Katalisator Indion 225 Na 5(2), 35-39 (2010)

3. Hou, Henan Huagon, New Process for synthesis of Triacetin, 15(6), 18-19 (1998)

4. M. Zang, X. Yuan, Hecheng Huaxue, Synthesis of Glycerol Triacetate Catalized by Phosphotungstic Acid 9 (5), 469-472 (2001)

5. G.F.C. Goncalves, B.P. Pinto, J.C. Silva, C.J.A. Mota, Catal. Today, Acetylation of glycerol catalyzed by different solid acids 133-135, 673-677 (2008)

6. D. Gelosa, M. Ramaioli, G. Valente, M. Morbidelli, Ind. Eng. Chem. Res. Chromatographic Reactors: Esterification of Glycerol with Acetic Acid Using Acidic Polymeric Resins 42, 6536-6544 (2003)

7. J.A. Melero, R.V. Grieken, G. Morales, M. Paniagua, Energ Fuel, Acidic Mesoporous Silica for the Acetylation of Glycerol : Synthesis of Bioadditives to Petrol Fuel, 21, 1782-1791 (2007)

8. J.I. Choi, W.H. Hong, H.N. Cham, Int. J. Chem. Kinet, Reaction Kinetics of Lactic Acid with Methanol Catalyzed by Acid Resins 28, 37-41 (1996)

9. Z. Lu, W. Ma, 1991, Study on Esterification reaction (1), Esterification of Glycerin with Acetic Acid using Ion Exchage Resin and Drying Agent as Catalysts (2), 53-56 (1991)

10. A.A. Kiss, A.C. Dimian, Adv. Synth. Catal, Solid Acid Catalyst for Biodiesel Production Towards Sustainable Energy 348, 75-81 (2006)

11. N. Sari, Z. Helwani, H. Rionaldo, Jom F Teknik, Esterifikasi Gliserol Dari Produk Samping Biodiesel Menjadi Triasetin Menggunakan Katalis Zeolit Alam 2(1), 1-7 (2015)

12. Zhu, Shanhui, X. Gao, D. Fang, Y. Zhu, Z. Hongyan, Y. Li, J Catal, Design of a highly active silverexchanged phosphotungstic acid catalyst for glycerol esterification with acetic acid 306, 155-163 (2013)

13. X. Gao, S. Zhu, Y. Li, (2015), Catal Commun, Graphene oxide as a facile solid acid catalyst for the production of bioadditives from glycerol esterification 62, 48-51 (2015)

14. H. Satriadi, Jurnal Teknik, Kinetika Reaksi Esterifikasi Gliserol Dan Asam Asetat Menjadi Triacetin Menggunakan Katalis Asam Sulfat 36, 75 $80(2015$ 